\title{
Avifaunal Diversity in Three Selected Habitats, at the Eastern Boarder of the Faculty of Applied Sciences of Rajarata University, Sri Lanka
}

\author{
D. Bopearachchi*, S. Wickramasinghe \\ Faculty of Applied Sciences, Rajarata University, Sri Lanka \\ *dilinibopearachchi@yahoo.com
}

\begin{abstract}
Sri Lanka's avifauna is one of the richest in Asia. Numerous researches were conducted on avifauna of Sri Lanka. However, most of the studies were confined to the wet zone and information on the dry zone is scare. The Faculty of Applied Science locates adjacent to the Mihintale Sanctuary, provides habitats for different species of birds. The present study aimed to identify the species diversity and feeding ecology of avifauna in three different habitats at the eastern border of the Faculty of Applied Sciences. The current study was conducted in the morning from 06:00 to 07:30 hrs and 16:30 to 18:00 hrs in the evening during the period from July to October 2014 . Line transect method $(200 \times 50 \mathrm{~m})$ was used for sampling forest edge, while point counts were used for sampling semi-aquatic habitat and grassland. Thirty minutes were spent at both points and transect count methods. The area covered during sampling was $500 \times 30 \mathrm{~m}$. Altogether, 45 birds belong to 21 families were recorded, including 42 breeding residents, four winter visitors and four endemic species. Out of 45 birds, 31 were very common, 14 were common and three were nationally threatened. Shannon Diversity Index $\left(\mathrm{H}^{\prime}\right)$ for edge, semi-aquatic and grassland were 2.91, 3.31 and 2.67 respectively. Species composition of three habitats, 6,5 and 12 bird species were confined to grassland, edge and semi aquatic area. Ocyceros gingalensis, Pycnonotus cafer and Megalaima zeylanica species were common to three habitats. Seven major feeding categories were observed within the study site. Majority was insectivores (29\%) and lowest was piscivores (4\%). The three different types of habitats in the study site provide suitable habitats for a variety of birds. Morning hours are more preferred time for the bird species, because of high food availability than in the evening. Higher bird diversity occurs in semi-aquatic area because of greater diversity of plant species composition. Variation of species richness may be due to the structural changes of vegetation, availability of food resources, climatic factors and human influences. Burning of grassland and waste disposal were the main threats to avifaunal distribution within the study site. Hence, avifaunal diversity in the study area needs to be conserved by taking steps to reduce habitat destruction.
\end{abstract}

Keywords: Avifauna; diversity, Mihintale, Feeding, Species

Proceedings of the International Forestry and Environment Symposium 2015 of the Department of Forestry and Environmental Science, University of Sri Jayewardenepura, Sri Lanka 